\title{
Análise bioquímica de calos de pinhão-manso
}

\author{
Biochemical analysis of callus from physic nut
}

\author{
Dalilhia Nazaré dos Santos ${ }^{\mathrm{I} *}$ Claudinéia Ferreira Nunes ${ }^{\mathrm{I}}$ Moacir Pasqual $^{\mathrm{I}}$ \\ Thaís Cainã Teixeira Valente ${ }^{\text {II }}$ Ana Catarina Lima de Oliveira ${ }^{\text {II }}$ \\ Neidiquele Maria SilveiraII
}

\section{RESUMO}

O pinhão-manso (Jatropha curcas L.) vem ganhando importância por seu potencial como insumo ao biodiesel. Estudos visam à adequação agronômica e a cultura de tecidos contribui indiretamente com este aspecto, auxiliando em pesquisas aplicadas como em biotecnologia, em situações que visam à regeneração de plantas. Nesse intuito, é fundamental avaliar, durante os periodos de cultivo dos calos, o comportamento dos metabólitos primários. A massa calogênica, por ocasião da inoculação, não apresentou reserva na forma de carboidratos. Aos 42 dias iniciou a absorção da sacarose do meio, enquanto o acúmulo no explante ocorreu a partir dos 98 dias de cultivo. O teor de aminoácidos foi alto no dia da inoculação e, por volta dos 98 dias, tanto os níveis de aminoácidos quanto os de proteínas decresceram.

Palavras-chave: Jatropha curcas L., carboidratos, proteinas, aminoácidos.

\section{ABSTRACT}

The physic nut (Jatropha curcas L.) is gaining importance because of its potential as raw material for biodiesel. Studies aiming the adequacy of agronomic techniques and tissue culture contribute, indirectly, to this aspect, helping applied research as biotechnology, in situations that aim plant regeneration. Therefore, it is essential to evaluate, the behavior of primary metabolites during the callus growing season. The callus mass at the inoculation time showed no carbohydrates reserve. At the $42^{\text {nd }}$ day the sucrose absorption started in the medium, while the accumulation in the explant occurred from the $98^{\text {th }}$ day of cultivation. Amino acid content was high at the inoculation's day and around the $98^{\text {th }}$ day, both amino acids and protein levels decreased.

Key words: Jatropha curcas L., carbohydrates, proteins, amino acids.

\section{INTRODUÇÃO}

A biomassa vegetal foi e é vital ao desenvolvimento da humanidade. Recentemente, busca-se o uso da biomassa vegetal como insumo na produção de biocombustíveis. Dentre as espécies cotadas, tem-se o pinhão-manso (Jatropha curcas L.) que se destaca por várias características, entre elas, o fato de ser uma cultura não alimentar, evento ocasionado pela presença de substâncias tóxicas como a proteína curcina (QIN et al., 2010).

Para que o pinhão-manso tenha pleno uso agrícola, os aspectos comportamentais da planta precisam ser esclarecidos, seja em nível de campo ou a nível laboratorial. Para este último, a cultura de tecidos vem contribuir, associada a ferramentas bioquímicas.

Segundo SMITH (2000), a cultura de tecidos constitui uma importante ferramenta para estudos básicos, como a compreensão dos fatores responsáveis pelo crescimento, metabolismo, diferenciação e morfogênese das células vegetais. Nesse contexto, o estudo da fisiologia de calos permite que o estabelecimento de massas calogênicas seja mais efetivo, pois desvenda aspectos do crescimento e desenvolvimento do explante. Tal conhecimento auxilia em pesquisas aplicadas, como em biotecnologia, válido a técnicas que permeiam a regeneração de explantes.

Para THORPE (2007), a cultura de tecidos tem assumido grande importância nos estudos de

'Departamento de Agricultura, Universidade Federal de Lavras (UFLA), CP 3037, 37200-000, Lavras, MG, Brasil. E-mail: dalilhia@yahoo.com.br.*Autor para correspondência.

"Departamento de Biologia, UFLA, Lavras, MG, Brasil. 
biotecnologia agrícola e é uma importante ferramenta no estudo de áreas básicas da biologia e bioquímica de plantas.

Segundo MESQUITA et al. (2002), o conhecimento de mudanças bioquímicas e fisiológicas, que ocorrem durante o crescimento in vitro de tecidos vegetais de espécies lenhosas, pode fornecer importantes informações relacionadas ao processo de estabelecimento e, consequentemente, propiciar a otimização das condições para seu cultivo in vitro.

Os carboidratos, proteínas e aminoácidos são os considerados metabólitos primários. Os carboidratos fornecem esqueletos de carbono e energia para a biossíntese de compostos orgânicos envolvidos no metabolismo celular e, de acordo com PASSOS (1996), a determinação de seus níveis revela a reserva prontamente disponível ao crescimento da planta e possui várias aplicações em estudos fisiológicos.

Estudos relacionados com o metabolismo das proteínas são importantes para um melhor entendimento dos processos que desencadeiam o desenvolvimento do explante. Estes servem para promover uma renovação tanto da investigação da biologia desses processos complexos quanto para gerar oportunidades para novas pesquisas (ORI, 2006).

Como os metabólitos primários são essenciais no desenvolvimento de explantes in vitro e o conhecimento dos níveis destes durante o desenvolvimento de calos contribui potencialmente para o conhecimento da fisiologia morfogenética, o objetivo do presente trabalho foi determinar os teores de carboidratos (açúcar solúvel total, açúcar redutor e amido), proteína e aminoácidos durante os períodos de cultivo de calos de pinhão-manso.

\section{MATERIAL E MÉTODOS}

O experimento foi desenvolvido no laboratório de Cultura de Tecidos Vegetais do Departamento de Agricultura da Universidade Federal de Lavras (UFLA).

Foram utilizadas, como material vegetal, sementes colhidas na safra de 2008 , provenientes da matriz Oracília, do banco de germoplasma do campo comercial no município de Janaúba (MG), cedidas pela empresa NNE Minas Agroflorestal.

Plântulas obtidas por meio de germinação in vitro foram utilizadas como fonte de explantes foliares, as quais tiveram suas folhas cotiledonares seccionadas em média com $1 \mathrm{~cm}^{2}$ por meio de bisturi, em ambiente estéril de câmara de fluxo laminar. Tais seções foram inoculadas em tubo de ensaio contendo meio MS (MURASHIGE \& SKOOG, 1962), suplementado com 1,0mg L-1 de 2,4-D (SANTOS, 2010).
O meio foi preparado com adição de $30 \mathrm{~g} \mathrm{~L}^{-1}$ de sacarose e solidificado com $5,5 \mathrm{~g} \mathrm{~L}^{-1}$ de ágar, antes da autoclavagem, que ocorreu a $121^{\circ} \mathrm{C}$ por $20 \mathrm{~min}$. Posteriormente, as culturas foram acondicionadas em armário de metal, propiciando a ausência de luz, em sala de crescimento a $25 \pm 2{ }^{\circ} \mathrm{C}$. As culturas foram repicadas duas vezes, em intervalos de 30 dias e, após a segunda repicagem, estabeleceu-se a curva de crescimento dos calos, segundo SANTOS (2010).

A avaliação bioquímica dos calos seguiu esta curva obedecendo a seus intervalos de avaliação. Ou seja, procedeu-se à coleta de $500 \mathrm{mg}$ de calos em intervalos de sete dias, desde o dia da inoculação $(0,7$, 14, 21, 28, 35, 42, 49, 56, 63, 70, 77, 84, 91, 98, 105 e 112 dias). Assim, constituíram-se 16 tratamentos, com três repetições, sendo cada repetição formada pela média de três tubos e cada tubo contendo um explante. As amostras de calos foram armazenadas em freezer à temperatura de $-80^{\circ} \mathrm{C}$ para futuras extrações e quantificações.

O extrato vegetal foi obtido por homogeneização em graal de uma amostra de 500mg (peso da matéria fresca) de calos em $4 \mathrm{~mL}$ de água. $\mathrm{O}$ extrato foi levado a banho-maria a $40^{\circ} \mathrm{C}$ por 30 minutos. Posteriormente, foi centrifugado a $4.800 \mathrm{~g}$ durante 30 minutos, ressuspendidos com mais $4 \mathrm{~mL}$ de água, totalizando um volume de $8 \mathrm{~mL}$ de extrato vegetal. Para a extração do amido, o pellet foi novamente ressuspendido com $8 \mathrm{~mL}$ do tampão acetato de potássio $200 \mathrm{mM}, \mathrm{pH} 4,8$, e colocado em banho-maria $\left(100^{\circ} \mathrm{C}\right)$ por 5 minutos. Em seguida, foram adicionadas 16 unidades da enzima amiloglucosidase e novamente incubado em banho-maria a $40^{\circ} \mathrm{C}$ por duas horas. Após a centrifugação a $5.000 \mathrm{~g}$ por 20 minutos, o sobrenadante foi coletado e o volume completado para $15 \mathrm{~mL}$.

A metodologia descrita por YEMM \& WILLIS (1954) foi utilizada para determinar o teor de açúcares solúveis totais (AST). Utilizaram-se alíquotas de $0,02 \mathrm{~mL}$ de extrato, aos quais foram adicionados $0,98 \mathrm{~mL}$ de água destilada e $2 \mathrm{~mL}$ do reagente antrona (20mg de antrona, $0,5 \mathrm{~mL}$ de água destilada e $10 \mathrm{~mL}$ de ácido sulfúrico concentrado). Após agitação, os tubos foram aquecidos a $100^{\circ} \mathrm{C}$, por 5 minutos. As amostras foram submetidas à análise em espectrofotômetro a $620 \mathrm{~nm}$ e a quantificação dos açúcares baseou-se na curva padrão de glicose. Para quantificação do amido, também se utilizou a metodologia descrita por YEMM \&WILLIS (1954).

Seguiu-se a metodologia descrita por MILLER (1959) para determinação dos açúcares redutores (AR). Dos extratos de calos, foram retiradas alíquotas de $0,5 \mathrm{~mL}$, adicionados $0,25 \mathrm{~mL}$ de água e $0,5 \mathrm{~mL}$ do reagente DNS (ácido 3,5-dinitrosalicílico). Com 
auxílio de agitador, homogeneizou-se a mistura a qual permaneceu em banho-maria a $100^{\circ} \mathrm{C}$ por 5 minutos, resfriando-se posteriormente à temperatura ambiente. As amostras foram submetidas à análise em espectrofotômetro a $540 \mathrm{~nm}$ e a quantificação dos açúcares baseou-se na curva padrão.

A quantificação das proteínas solúveis totais foi realizada pelo método de BRADFORD (1976). Em alíquotas de $0,1 \mathrm{~mL}$ do extrato bruto, foram adicionados água destilada e $5 \mathrm{~mL}$ do reagente Comassie Blue (constituído de $0,01 \%$ de Comassie Blue $\mathrm{G}-250,8,5 \%$ de ácido fosfórico e $4,7 \%$ de etanol). As amostras foram submetidas à análise em espectrofotômetro a $595 \mathrm{~nm}$ e a quantificação das proteínas baseou-se na curva padrão.

Para determinação dos teores de aminoácidos, foi utilizado o método da ninhidrina (STEIN \& MOORE, 1948). Adicionou-se, em tubos de ensaio, uma alíquota de $0,2 \mathrm{~mL}$ do extrato, juntamente com $1,7 \mathrm{~mL}$ do reagente $\mathrm{A}+\mathrm{B}+\mathrm{C}(\mathrm{A}$ - tampão citrato de sódio $0,2 \mathrm{M}, \mathrm{pH} 5,0 ; \mathrm{B}$ - reagente de ninhidrina $5 \% \mathrm{em}$ metilcelossolve e $\mathrm{C}-\mathrm{KCN} 2 \%$ em metilcelossolve). Os tubos foram agitados e colocados em banho-maria a $100^{\circ} \mathrm{C}$, durante 20 minutos. Após o resfriamento, foi adicionado $1,3 \mathrm{~mL}$ de etanol $60 \%$ (v/v) em cada tubo. Realizou-se a leitura em espectrofotômetro no comprimento de onda $570 \mathrm{~nm}$. A quantificação dos aminoácidos baseou-se na curva.

Os dados foram submetidos à análise de variância, utilizando software Sisvar ${ }^{\circledR}$ (FERREIRA, 2000), através do teste de Scott-Knott a 5\% de significância.

\section{RESULTADOS E DISCUSSÃO}

Analisando-se individualmente os AST (açúcar solúvel total), nota-se que os teores se mantêm baixos desde o dia da inoculação até os 77 dias de cultivo (Tabela 1). Ao final do cultivo, têm-se teores consideráveis de AST, mesmo que de forma secundária. Resultados elevados e também tardios em função do período de cultivo para AST igualmente foram obtidos por AZEVEDO (2003), aos 84 dias de cultivo de calos de copaíba (Copaifera langsdorffii). Com relação aos teores de AR (açúcares redutores), observa-se que inicialmente também foram baixos, até os 35 dias, e posterior aumento dos 63 até os 77 dias. Ao término do cultivo, os teores são elevados desde os 98 até os 112 dias finais (Tabela 1).

Períodos semelhantes de maior teor de AR foram identificados por ABBADE (2008), aos 45 dias de cultivo de calos de ipê branco (Bertholletia excelsa),
Tabela 1 - Teores de carboidratos de calos de $\boldsymbol{J}$. curcas formados a partir de explantes foliares, inoculados em meio MS suplementado com 1,0mg L ${ }^{-1}$ de 2,4-D, durante 112 dias de cultivo, expresso em teor por massa fresca (MF). AST - Açúcares Solúveis Totais; AR - Açúcares Redutores; Amido.*

\begin{tabular}{lccc}
\hline $\begin{array}{c}\text { Dias de } \\
\text { cultivo }\end{array}$ & $\begin{array}{c}\text { AST } \\
\left(\mathrm{mg} \mathrm{g}^{-1} \mathrm{MF}\right)\end{array}$ & $\begin{array}{c}\text { AR } \\
\left(\mathrm{mg}^{-1} \mathrm{MF}\right)\end{array}$ & $\begin{array}{c}\text { Amido } \\
\left(\mathrm{mg} \mathrm{g}^{-1} \mathrm{MF}\right)\end{array}$ \\
\hline 0 & $2,3167 \mathrm{~g}$ & $0,076 \mathrm{c}$ & $0,093 \mathrm{~d}$ \\
7 & $2,3706 \mathrm{~g}$ & $0,067 \mathrm{c}$ & $0,084 \mathrm{~d}$ \\
14 & $2,6765 \mathrm{e}$ & $0,071 \mathrm{c}$ & $0,104 \mathrm{c}$ \\
21 & $2,0937 \mathrm{~h}$ & $0,071 \mathrm{c}$ & $0,112 \mathrm{c}$ \\
28 & $2,2543 \mathrm{~g}$ & $0,074 \mathrm{c}$ & $0,091 \mathrm{~d}$ \\
35 & $2,0907 \mathrm{~h}$ & $0,082 \mathrm{~b}$ & $0,088 \mathrm{~d}$ \\
42 & $2,9769 \mathrm{~d}$ & $0,115 \mathrm{a}$ & $0,097 \mathrm{c}$ \\
49 & $2,6676 \mathrm{e}$ & $0,087 \mathrm{~b}$ & $0,087 \mathrm{~d}$ \\
56 & $2,7033 \mathrm{e}$ & $0,087 \mathrm{~b}$ & $0,082 \mathrm{~d}$ \\
63 & $3,2327 \mathrm{c}$ & $0,098 \mathrm{a}$ & $0,148 \mathrm{~b}$ \\
70 & $3,0304 \mathrm{~d}$ & $0,102 \mathrm{a}$ & $0,142 \mathrm{~b}$ \\
77 & $3,6223 \mathrm{a}$ & $0,107 \mathrm{a}$ & $0,093 \mathrm{~d}$ \\
84 & $2,7747 \mathrm{e}$ & $0,092 \mathrm{~b}$ & $0,119 \mathrm{c}$ \\
91 & $2,4981 \mathrm{f}$ & $0,082 \mathrm{~b}$ & $0,073 \mathrm{~d}$ \\
98 & $3,3189 \mathrm{~b}$ & $0,109 \mathrm{a}$ & $0,168 \mathrm{a}$ \\
105 & $3,3368 \mathrm{~b}$ & $0,122 \mathrm{a}$ & $0,103 \mathrm{c}$ \\
112 & $3,1792 \mathrm{c}$ & $0,109 \mathrm{a}$ & $0,104 \mathrm{c}$ \\
\hline
\end{tabular}

* Médias seguidas por letras iguais na coluna não diferem entre si, pelo teste de Scott-Knott, a 5\% de probabilidade.

enquanto que, para lechieira (Litchi chinesis Sonn.), este ocorreu aos 70 dias de cultivo (MESQUITA et al., 2002).

Alguns autores notaram que o cultivo de calos induziu a uma diminuição nos teores dos açúcares, como em castanha do Brasil (SERRA et al., 2000); café (SANTOS et al., 2003) e murici-pequeno (NOGUEIRA et al., 2008). No presente trabalho, observou-se que tanto os AST quanto os AR tem como tendência baixo teor a partir da inoculação e nível superior nos períodos finais de cultivo, contrariando as observações anteriores. Deve-se considerar que o explante utilizado tratava-se de calo que praticamente não possuía reservas na forma de carboidratos, enquanto os demais autores partem de tecido foliar como explante inicial, no qual, segundo ABBADE (2008), o elevado teor de açúcares, inicialmente, pode estar relacionado aos contidos nas folhas da planta mãe, fornecedora do explante, que supre a demanda metabólica do crescimento do calo.

Relacionando-se com o cultivo in vitro, os AR têm seu pico aos 42 dias de cultivo, indicando que houve uma absorção anterior da sacarose do meio e posterior degradação em açúcares menores, o que ocorre de forma geral até 112 dias finais. O pico de AR 
no final do cultivo não contribui para incrementos em AST. Isso indica que nem todos os AR disponíveis contribuem para a síntese de hexoses ligadas, demonstrando que os açúcares associados como sacarose e outros, são sintetizados pelos AR até os 70 dias, depois desse período os mesmos são degradados pela respiração do tecido em açúcares menores, contribuindo para o incremento em AR, observado ao final do cultivo.

Em relação aos carboidratos insolúveis (Tabela 1), observa-se que os níveis de amido foram baixos, desde o dia da inoculação até os 91 dias de cultivo. O reduzido teor de amido na inoculação, juntamente com AST e AR, vem confirmar que provavelmente o calo utilizado era desprovido de reservas carboidratadas. Como explantes cultivados in vitro são praticamente heterotróficos, o acúmulo de reservas realmente não é a rota marcante em seu metabolismo (CHAGAS et al., 2003).

De acordo com SILVEIRA et al. (2004), em suspensões celulares de Pinus tadea L., os níveis de amido foram reduzidos mediante a adição de 2,4-D ao cultivo. Como o cultivo dos calos de J.curcas foi iniciado em meio contendo tal regulador, este pode ter influenciado de forma semelhante. NOGUEIRA (2006), avaliando o teor de amido por períodos de cultivo em murici-pequeno, também observou baixos teores de amido no cultivo inicial, do mesmo modo, com a adição de 2,4-D ao meio de cultura.

A relação entre os níveis de AST e AR nos explantes é indicativo para a formação ou degradação do amido durante seu desenvolvimento. $\mathrm{O}$ amido exibiu maior teor aos 98 dias de cultivo. Como se sabe, a síntese de amido é diretamente dependente da disponibilidade de AST eAR, pois o amido é formado pela polimerização de moléculas de glicose em ligações $\alpha 1-4$ e $\alpha 1-6$ (CASTRO et al., 2009). Relacionando-se o fato à informação, entende-se o porquê de seu aparecimento ocorrer somente nos períodos finais de cultivo.

Para proteínas, foram observados níveis inferiores até os 63 dias de cultivo (Tabela 2). Aos 70 e 98 dias de cultivo, notaram-se maiores teores de proteínas totais, informação que não corrobora com a resposta obtida para outras lenhosas, como sangra d'água e ipê branco, nos quais o melhor teor de proteína foi detectado no início do cultivo (LIMA et al., 2007; ABBADE, 2008). O aumento no teor de proteínas indica mudanças no metabolismo celular, os quais geram a necessidade de proteínas específicas para garantir que suas funções sejam executadas (MULLER, 2008).

Os baixos teores de proteínas ao final do cultivo, dos 105 aos 112 dias, coincidem com elevados teores de AR. Segundo MURTHY \& SUN (2000), níveis
Tabela 2 - Teores de Proteínas totais e Aminoácidos de calos de $\boldsymbol{J}$. curcas formados a partir de explantes foliares, inoculados em meio MS suplementado com $1,0 \mathrm{mg} \mathrm{L}^{-1}$ de 2,4-D, durante 112 dias de cultivo, expressa em teor por massa fresca (MF).

\begin{tabular}{ccc}
\hline Dias de cultivo & $\begin{array}{c}\text { Proteína } \\
\left(\mathrm{mg} \mathrm{g}^{-1} \mathrm{MF}\right)\end{array}$ & $\begin{array}{c}\text { Aminoácido } \\
\left(\mathrm{m} \mathrm{mol} \mathrm{g}^{-1} \mathrm{MF}\right)\end{array}$ \\
\hline 0 & $0,0144 \mathrm{~d}$ & $0,5398 \mathrm{a}$ \\
7 & $0,0042 \mathrm{~g}$ & $0,4318 \mathrm{c}$ \\
14 & $0,0074 \mathrm{f}$ & $0,4374 \mathrm{c}$ \\
21 & $0,0093 \mathrm{f}$ & $0,3384 \mathrm{~d}$ \\
28 & $0,0093 \mathrm{f}$ & $0,1824 \mathrm{f}$ \\
35 & $0,0018 \mathrm{~h}$ & $0,2672 \mathrm{e}$ \\
42 & $0,0023 \mathrm{~h}$ & $0,4247 \mathrm{c}$ \\
49 & $0,0042 \mathrm{~g}$ & $0,4134 \mathrm{c}$ \\
56 & $0,0176 \mathrm{c}$ & $0,3273 \mathrm{~d}$ \\
63 & $0,0119 \mathrm{~b}$ & $0,5759 \mathrm{a}$ \\
70 & $0,0259 \mathrm{a}$ & $0,4466 \mathrm{c}$ \\
77 & $0,0056 \mathrm{~g}$ & $0,4677 \mathrm{c}$ \\
84 & $0,0138 \mathrm{~d}$ & $0,4189 \mathrm{c}$ \\
91 & $0,0117 \mathrm{e}$ & $0,2745 \mathrm{e}$ \\
98 & $0,0261 \mathrm{a}$ & $0,4979 \mathrm{~b}$ \\
105 & $0,0137 \mathrm{~d}$ & $0,4167 \mathrm{c}$ \\
112 & $0,008 \mathrm{f}$ & $0,2134 \mathrm{f}$ \\
\hline
\end{tabular}

* Médias seguidas por letras iguais na coluna não diferem entre si, pelo teste de Scott-Knott, a 5\% de probabilidade.

elevados de AR podem causar alterações químicas em proteínas por meio das reações de Amadori e Mailhard, que consiste numa reação entre o grupamento carbonila dos AR com o grupamento amino das proteínas, reação que ocorre sem a necessidade de ser mediada por enzimas. Uma questão que dá respaldo a essa informação é o fato de que a umidade elevada favorece a ocorrência da reação de Amadori e Mailhard (WETTLAUFER \& LEOPOLD, 1991). Ao cultivo in vitro, é característico o ambiente de alta umidade, consequentemente, tais reações são favorecidas, inativando as proteínas e, portanto, reduzindo seus teores nos tecidos.

Apesar da redução nos teores de proteínas, aparentemente isso não ocorre com os AR, mesmo que estes estejam envolvidos numa mesma ligação. Provavelmente, tal fato não foi identificado porque o nível de AR é muito maior que o de proteínas, cerca de dez vezes mais, permitindo que a quantidade de AR que se envolveram em ligações com proteínas fosse $o$ suficiente para inativar essas últimas, mas não para inferiorizar a quantificação de AR aos 105 e 112 dias.

Com relação aos aminoácidos, os níveis foram elevados no dia da inoculação, reduzindo drasticamente até os 28 dias (Tabela 2). A elevada 
concentração de aminoácido por ocasião da inoculação é possivelmente devido ao conteúdo endógeno do explante, o qual vai se exaurindo até os 28 dias. A partir desse período, os teores de aminoácido se elevam até os 63 dias, indicando que nesse intervalo ocorre a absorção dos aminoácidos adicionados ao meio de cultura.

A partir dos 63 dias, os níveis decaem até o final do cultivo. Portanto, é nesse ponto que cessa a absorção, sendo um indicativo do início da senescência ou possivelmente seja devido às reações de Amadori e Mailhard, pois, assim como nas proteínas, os aminoácidos possuem um grupamento amino disponível à reação com a carbonila do AR. Em calos de ipê branco, ABBADE (2008) notou que os teores de aminoácidos se elevaram até o $15^{\circ}$ dia, mesmo período identificado por SERRA et al. (2000) em segmentos foliares de castanha do Brasil.

No presente trabalho, enquanto nos dias iniciais de cultivo os teores de aminoácidos eram altos, os de carboidratos solúveis foram baixos. Esses resultados contrários podem significar que os carboidratos solúveis foram consumidos durante $o$ processo de redução do nitrogênio para a formação de compostos aminados como os aminoácidos. Para MESQUITA et al. (2002), o aumento nos teores de aminoácidos pode ser devido a uma absorção considerável do nitrogênio e de glicina do meio de cultura. Segundo GEORGE et al. (1988), a presença de amônio no meio de cultura resulta no aumento da síntese de aminoácidos e proteínas, os quais, geralmente, são produzidos utilizando energia liberada no catabolismo dos carboidratos.

\section{CONCLUSÃO}

A massa calogênica inoculada é desprovida de reservas na forma de carboidratos, sendo que os calos iniciam a absorção da sacarose adicionada ao meio aos 42 dias e o acúmulo desta no explante ocorre a partir dos 98 dias de cultivo. O nível de aminoácidos é alto no dia da inoculação, o qual, juntamente com a proteína, decresce a partir dos 98 dias até o final do cultivo.

\section{REFERÊNCIAS}

ABBADE, L.C. Aspectos do cultivo in vitro de ipê-branco. 2008. 113f. Dissertação (Mestrado em Fisiologia Vegetal) Programa de Pós-graduação em Fisiologia Vegetal, Universidade Federal de Lavras, MG.

AZEVEDO, K.S. Indução e análise bioquímica de calos e aspectos da anatomia foliar de copaíba (Copaifera langsdorffii). 2003. 86f. Dissertação (Mestrado em Fisiologia
Vegetal) - Programa de Pós-graduação em Fisiologia Vegetal, Universidade Federal de Lavras, MG.

BRADFORD, M.M. A rapid and sensitive method for the quantification of microgram quantities of protein utilizing the principle of protein-dye binding. Analytical Biochemistry, New York, v.72, p.248-254, 1976.

CASTRO, E.M. de et al. Histologia vegetal: estrutura e função de órgãos vegetativos. Lavras: UFLA, 2009. 1v.

CHAGAS, E.A. et al. Development of globular embryos from the hybridization between 'Pêra Rio' sweet orange and 'Poncã' mandarin. Revista Brasileira de Fruticultura, Jaboticabal, v.25, n.3, p.483-488, 2003. Disponível em: <http: //www.scielo.br/ $\mathrm{pdf} / \mathrm{rbf} / \mathrm{v}$ 25n3/18674.pdf>. Acesso em: 10 set. 2010. doi: 10.1590/ S0100-29452003000300031.

FERREIRA, D.F. SISVAR - sistema de análise estatístic. Lavras: UFLA/DEX, 2000. version 4.3.

GEORGE, E.F. et al. Plant culture media: commentary and analysis. England: Exegetics, 1988. 1v.

LIMA, E.C. et al. Avaliação bioquímica do desenvolvimento de calos in vitro a partir de segmentos foliares de Sangra d'água (Croton urucurana Baill.). Magistra, Cruz das Almas, v.19, n.3, p.184190, 2007. Disponível em: <http:// www.magistra. ufrb.edu .br/ 3 07_19_3.html>. Acesso em: 20 ago. 2009.

MESQUITA, A.C. et al. Análises bioquímicas de calos obtidos de segmentos foliares de lechieira (Litchi chinesnsis Sonn.). Magistra, Cruz das Almas, v.14, n.1, p.1-6, 2002. Disponível em: $<$ http://www.magistra.ufrb.edu.br/3_02_14.html $>$. Acesso em: 5 mai. 2009.

MILLER, G.L. Use of dinitrosalicylic acid reagent for determination of reducing sugar. Analytical Biochemistry, New York, v.31, n.3, p.426-428, 1959.

MULLER, T.S. Fisiologia e metabolismo da embriogênese somática e zigótica de Acca sellowiana (Berg) Burret. 2008. 92f. Dissertação (Mestrado em Ciências) - Programa de Pósgraduação em Recursos Genéticos Vegetais, Universidade Federal de Santa Catarina, SC.

MURASHIGE, T.; SKOOG, F. A revised medium for rapid growth and bioassays with tobacco tissue cultures. Physiologia Plantarum, Copenhagen, v.15, n.3, p.473-497, 1962.

MURTHY, U.M.N.; SUN, W.Q. Protein modification by Amadori and Maillard reactions during seed storage: roles of sugar hydrolysis and lipid peroxidation. Journal of Experimental Botany, Oxford, v.51, n.348, p.1221-1228, 2000. Disponível em: <http://jxb.oxfordjournals.org/54/384/ 1057>. Acesso em: 13 ago. 2009. doi: 10.1093/jxb/092.

NOGUEIRA, R.C. Caracterização de calos embriogênicos de murici-pequeno (Byrsonima intermedia A. Juss.). 2006. 41f. Tese (Doutorado em Fisiologia Vegetal) - Programa de Pós-graduação em Fisiologia Vegetal, Universidade Federal de Lavras, MG.

NOGUEIRA, R.C. et al. Curva de crescimento e análises bioquímicas de calos de murici-pequeno (Byrsonima intermedia A. Juss.). Revista Brasileira de Plantas Medicinais, 
Botucatu, v.10, n.1, p.44-48, 2008. Disponível em: < http:// www.ibb. unesp.br/rbpm /pdf v10 n1_2008/ >. Acesso em: 27 mar. 2009.

ORI, S.S. Influência das auxinas no desenvolvimento e no teor de carboidratos solúveis, amido e proteína total solúvel em Phalaenopsis amabilis (Lineu) Blume (Orchidaceae) cultivada in vitro. 2006. 133f. Dissertação (Mestrado em Biodiversidade Vegetal e Meio Ambiente)Instituto de Botânica da Secretaria de Estado do Meio Ambiente, S.P.

PASSOS, L.P. Métodos analíticos e laboratoriais em fisiologia vegetal. Coronel Pacheco: EMBRAPA/CNPGL, 1996. 1v.

QIN, X.B. et al. Different functions and expression profiles of Curcin and Curcin-L in Jatropha curcas L. Journal of Biosciences, Bangalore, v.65, p. 355-362, 2010. Disponível em: <http:// apps.isiknowledge.com/full\&doc=1\&cacheurlFromRightClick=no $>$. Acesso em: 25 jul. 2010.

SANTOS, C.G. et al. Indução e análise bioquímica de calos obtidos de segmentos foliares de Coffea arábica L., cultivar RUBI. Ciência e Agrotecnologia, Lavras, v.27, n.3, p.571-577, maio/ jun. 2003. Disponível em: <http://www.editora.ufla.br/revista/ 27_3/art11.PDF>. Acesso em: 9 out. 2009.

SANTOS, D.N. Caracterização de massas pró-embriogênicas em pinhão-manso (Jatropha curcas L.). 2010. $118 \mathrm{f}$. Dissertação (Mestrado em Fisiologia Vegetal) - Programa de Pósgraduação em Fisiologia Vegetal, Universidade Federal de Lavras., MG

SERRA, A.G.P. et al. Análises bioquímicas de calos formados de explantes foliares de castanha do Brasil (Bertholletia excelsa
H. B. K.). Ciência e Agrotecnologia, Lavras, v.24, n.4, p.833-840, 2000. Disponível em: <http://www.editora.ufla.br/ revista/244/art01.pdf>. Acesso em: 11 ago. 2009.

SILVEIRA, V. et al. Effect of plant growth regulators on the cellular growth and levels of intracellular protein, starch and polyamines in embriogenic suspension cultures of Pinus taeda. Plant Cell, Tissue and Organ Culture, Dordrecht, v.76, n.1, p.53-60, 2004. Disponível em: $<\mathrm{http}: / /$ www.springerlink. com/contente//jd6>. Acesso em: 12 jun. 2010. doi 10.1023/ A: 1025847515435 .

STEIN, W.; MOORE, S. A modified ninhydrin reagent for photometric determination of amino acids and related compounds. Journal of Biological Chemistry, Bethesda, v.176, n.2, p.367-372, 1948.

SMITH, R.H. Plant tissue culture: techniques and experiments. San Diego, California: Academic, 2000. 1v.

THORPE, T.A. History of plant tissue culture. Molecular Biotechnology. v.37, p.169-180, 2007. Disponível em: <http:/ /apps.isiknowledge.com/full_record.doproduct=WOS\&search $\mathrm{m}$ ode FromRightClick=no>. Acesso em: 26 jul. 2010. doi: 10.1007/s12033-007-0031-3.

WETTLAUFER, S.H.; LEOPOLD, A.C. Relevance of amadori and maillard products reactions to seed deterioration. Plant Physiology, Rockville, v.97, n.1, p165-169, 1991. Disponível em: <http://www.plantphysiol.org/cgi/reprint/97/1/165>. Acesso: 14 set. 2009. doi:10.1104/pp.97.1.165.

YEMM, E.W.; WILLIS, A.J. The estimation of carbohydrates in plant extracts by anthrone. Biochemical Journal, London, v.57, n.3, p.508-514, 1954. 